\title{
Basal skull fracture and the halo sign
}

\section{Ravi Sunder MD Kevin Tyler MD}

Competing interests: None declared.

This article has been peer reviewed.

Affiliations: From the Department of Emergency Medicine (Sunder), Royal Inland Hospital, Kamloops, $\mathrm{BC}$; and the Department of Radiology (Tyler), Queen's University, Kingston, Ont.

Correspondence to: Ravi Sunder, ravi.sunder @utoronto.ca

CMAJ 2013. DOI:10.1503 /cmaj.120055

A 27-year-old male driver in a singlevehicle rollover collision was transferred to a trauma centre after stabilization and endotracheal intubation at a community hospital. He had been wearing a seat belt. Other than notation of the patient's fluctuating score on the Glasgow Coma Scale and movement of his four limbs, a neurologic examination was not documented before intubation. After transfer, a bloody discharge was noted from his right external auditory canal, and the right tympanic membrane was perforated. The patient had no Battle sign (i.e., bruising over the mastoid process). The fluid from his ear dripped onto the bedsheet, showing a "halo" pattern (Figure 1). Computed tomography (CT) of the patient's head showed, among other injuries, a transverse fracture of the petrous segment of his right temporal bone (Appendix 1, available at www.cmaj.ca/lookup /suppl/doi:10.1503/cmaj.120055/-/DC1).

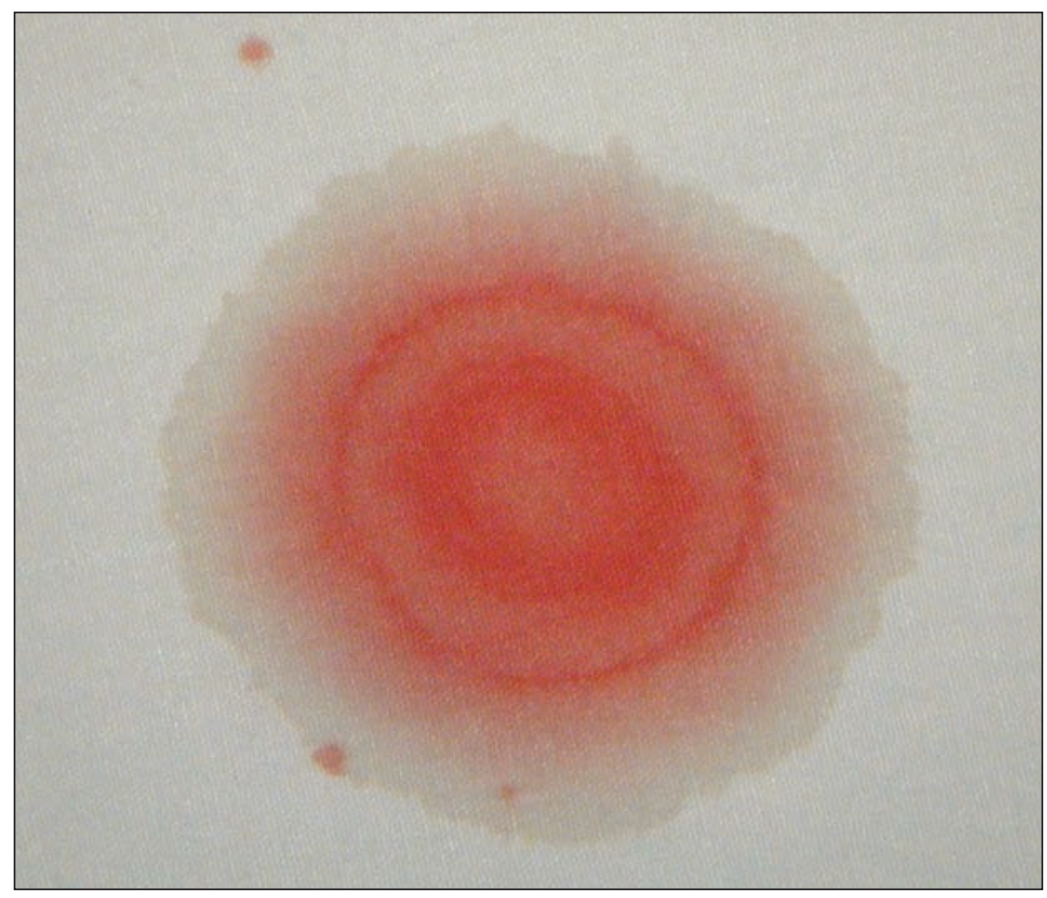

Figure 1: A halo pattern on a bedsheet produced by bloody otorrhea from a 27-year-old man who had been in a motor vehicle collision.
Basal skull fracture should be considered in all patients with head injuries, especially those with physical signs such as otorrhea, Battle sign or periorbital ecchymoses. "The "halo" or "double-ring" sign is a classic image in medicine and was taught as a method for determining whether bloody discharge from the ears or nose contained cerebrospinal fluid (CSF). This test uses the principle of chromatography: different components of a fluid mixture will separate as they travel through a material. Although the value of this sign has been debated, an experiment showed that the sign was consistently visible when CSF concentrations were 30\%-90\% when mixed with blood. ${ }^{2}$ However, the sign was not specific to CSF: mixtures of blood with saline, tears or rhinorrhea also produced halos; filter paper, paper towel, coffee filters and linen all showed a ring. ${ }^{2}$

Guidelines recommend a CT scan of the head when basal skull fracture is suspected. ${ }^{3}$ Although CSF leakage occurs in $2 \%-21 \%$ of basal skull fractures, a recent review does not support the use of prophylactic antibiotics to prevent the development of meningitis. ${ }^{4}$

\section{References}

1. Pretto Flores L, De Almeida C S, Casulari L A. Positive predictive values of selected clinical signs associated with skull base fractures. J Neurosurg Sci 2000;44:77-82, discussion 82-3.

2. Dula DJ, Fales W. The 'ring sign': Is it a reliable indicator for cerebral spinal fluid? Ann Emerg Med 1993;22:718-20.

3. Stiell IG, Wells GA, Vandemheen K, et al. The Canadian CT Head Rule for patients with minor head injury. Lancet 2001;357:1391-6.

4. Ratilal BO, Costa J, Sampaio C, et al. Antibiotic prophylaxis for preventing meningitis in patients with basilar skull fractures. Cochrane Database Syst Rev 2011;(8):CD004884.

Clinical images are chosen because they are particularly intriguing, classic or dramatic. Submissions of clear, appropriately labelled high-resolution images must be accompanied by a figure caption and the patient's written consent for publication. A brief explanation (250 words maximum) of the educational significance of the images with minimal references is required. 